\title{
spotlight on dental nurses
}

Below is a listing of post-qualification courses for dental nurses supplied by the British Association for Dental Nurses (BADN) and the National Examining Board for Dental Nurses (NEBDN).

Though this is not fully comprehensive it does include useful ideas and leads.

\section{Course details supplied by BADN}

NVQ Assessor award, Leeds

Contact Anne Riley on 01132336283

July 2004

Certificate in Dental Nurse Sedation, Sunderland

Contact Dawn Longmore/Claire Kelly on 01915109090

September 2004 - March 2005

Certificate in Special Care Dental Nursing, Leeds

Contact Anne Riley on 01132336283

November 2004

\section{Course details supplied by NEBDN}

The National Examining Board for Dental Nurses provides four post-certification awards that are available to qualified dental nurses who are on the current Voluntary National Register of Dental Nurses.

\section{Certificate in Dental Sedation Nursing}

This qualification is only suitable for candidates required to assist in the surgery during routine conscious sedation on a regular basis, as the completion of a Portfolio of Experience, including logsheets, is a requirement for the award. Theoretical knowledge and practical skills are also assessed through written papers and a practical/oral examination.

The examinations for the above awards are held on the 3rd Saturdays in March and September each year. Attendance on a training course is not obligatory but is recommended.

\section{Certificate in Orthodontic Nursing}

This is a qualification suitable for dental nurses who assist in orthodontic procedures.

These two awards are available only through NEBDN approved training centres. Underpinning knowledge and understanding are then assessed through written papers available in June and December each year.

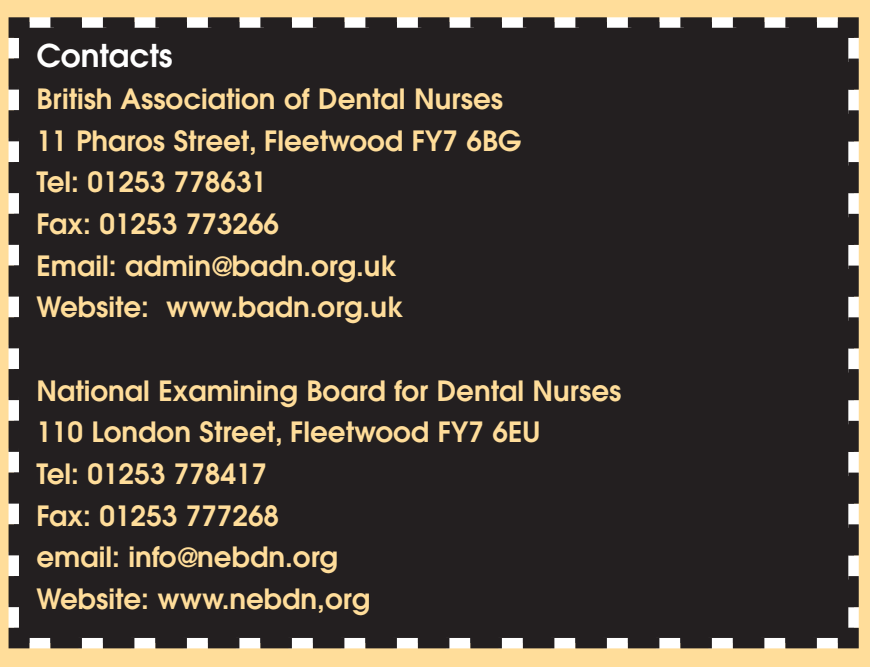

\section{Book review}

Advanced Dental Nursing, Robert Ireland (ed), Blackwell Munksgaard 2004 price $\mathfrak{E} 29.50$ ISBN 1405109238

This long-awaited textbook has been written by a team of authors with special interests and expert knowledge in their chosen fields. This is reflected in the depth and relevance of information presented.

It is divided into six chapters which include subjects allied to the NEBDN postcertificate courses - oral health education, special care, sedation and orthodontics. In addition to this there are also chapters on career development pathways and the future for dental nursing.

All of these are subjects which have long suffered from a lack of relevant text books. This book more than adequately fills the gap and presents many ideas for further study. Each chapter is clearly presented with its own contents page and includes recommended tasks to help the reader apply the information in a practical setting.

Overall, this is an excellent addition to the dental nurses' library.

Michelle Brindley, President-Elect BADN 